\title{
THE OREGON PLAN
}

\section{INTRODUCTION}

$\mathbf{T}$ he Oregon Plan has attracted worldwide attention although, at the time of writing, it had still to be enacted by the legislature. It is an attempt to face up to the rationing of health care by making the process by which access to health care is decided open, by seeking and taking into account community values for health care, and by determining the effectiveness and efficiency of health care interventions to inform these choices. These features of the plan have received much favourable comment, and many policymakers, practitioners and academics - have asked if it could be applied here.

In this paper, we describe the processes and problems involved in setting health care priorities in Oregon, review the success of such methods in achieving the aims of the plan and comment on the relevance of the Oregon approach to Australia.

\section{THE PROCESS}

In 1989 a coalition of legislators, policymakers and health care professionals created a plan that would try to deliver universal access to basic health care to all citizens of Oregon, US. At that time a significant proportion of Oregon's citizens was denied access to health care as they were either not privately insured for health care or not eligible for assistance under the federal schemes designed to provide access to care for the old, the disabled and the poor.

The Oregon Plan has three stages:

몸 priority setting; budget setting; and implementation.

The priority setting has attracted the most attention and provoked the most contention. The first attempt at setting priorities involved three processes:

- community consultation;

- identifying a list of conditions and possible treatments and determining the outcomes of treatment; and comparing the health gains (outcomes) of treatment with the costs to establish which treatments should be given priority, i.e. funding.

The result of combining the social values generated by the community consultation and the evaluation of the costs and outcomes of health care was a "draft" list of health care service priorities. Subsequent reviews of the draft list have changed the approach used in the construction of the final priority list, as described here.

\section{Community consultation}

The process of community consultation was designed to identify social values critical to setting health service priorities. There were two components to this process community meetings and a telephone survey. More than 1000 citizens attended a total of 47 community meetings. These meetings followed a set format and recorded the values of the participants in terms of such issues as longevity versus quality of life, preventive care versus treatment, care for the old versus the young. The critical social values which evolved from this process are shown in Table 1.

\section{TABLE 1}

1. Prevention

2. Quality of life

3. Cost effectiveness

4. Ability to function normally

5. Equity

6. Effectiveness of treatment

7. Benefit to many as opposed to few

8. Treatment of mental health problems and chemical dependency

9. Personal choice in treatment decisions

10. Community compassion

11. The impact on society

12. Length of life

13. Personal responsibility

Unfortunately, the sample of the population attending the public meetings was not representative of the Oregon population as a whole; 56 per cent of participants worked in the health care industry. It was even less representative of those whom the implementation of the plan would affect; less than 10 per cent of attendees had incomes which would classify them as living below the federal poverty level.

Quality of life was explored. Using a simplified classification of health outcomes (a modified version of the Quality of Well-Being Scale (QWB) developed by Kaplan and $\mathrm{Bush}^{1}$ ), values or weights were derived from a random telephone survey of 1000 people and site-specific surveys of disadvantaged groups. These weights were used to value different health outcomes from various treatments.

\section{Health outcomes}

Information about the outcomes of treatment for specified conditions was collected. Data were drawn from a review of the literature and from the deliberations of 54 panels of health care providers. These experts were asked to determine clinical effectiveness of treatment by specifying, for each condition, the probability of each health state (the states as described by the QWB) with and without treatment. The published outcome data were compared with the outcomes solicited from the panels of providers.

For a list of conditions/treatments, the expected health states after treatment were weighted by the values derived from the community survey. The resultant scores multiplied by the duration of the health state gave an estimate of the benefits of treatment, which many would recognise as Quality Adjusted Life Years (QALYs). These priorities were then modified according to the critical social values summarised in Table 1.

\section{Priorities}

Priorities were set using the economic evaluation approach. The costs of providing treatment were estimated by the Medicaid agency and other provider bodies. The cost per unit of health gain, or cost per QALY for each condition given treatment compared to no treatment, was then estimated. Priorities could be assigned by comparing costs and benefits, ranking treatments by cost per QALY.

This draft priority list was published but withdrawn in the face of widespread criticism. A revised list was developed. The new method involved developing sets of categories of expected health benefit from treatment, and assigning each condition and treatment pair to a category. The categories were ranked by the Health Services Commission (HSC) in order of their perceived importance to the individual, 
to society and by the "necessity" of the category. This approach ignores the cost per QALY ranking which would have indicated the costs and benefits of additional or marginal benefits. To a minor extent, cost was factored into the process as the final arrangement of the items within each category was done with some references to service costs.

This "final" list as constructed and approached by the Oregon Plan implies that all priority 1 services should be provided before any priority 2 services. That is, anyone eligible for heart surgery should be operated on before any hip replacements are funded. The final priority list was released in February 1991. As this list ignores costs to a large extent, the Oregon approach as currently formulated is not based on economic evaluation principles.

\section{PROBLEMS AND CRITICISMS}

\section{Community consultation}

The community consultation process involved an unrepresentative sample of Oregon citizens. Most of those involved in the public meetings were health care professionals. The extent to which the ensuing values do reflect those of the wider community is open to question. The group to be affected by the plan's health care rationing, those Medicaid beneficiaries and the poor without insurance, were under-represented.

\section{Costs and outcomes data}

Difficulties were encountered in obtaining data in three main areas of the "draft" prioritisation process. These were the categorisation of outcomes, the estimates of the frequency of outcomes and the estimation of costs.

The methodological problem (as opposed to data availability) in the construction of such a priority list is the identification of the margin. Economic evaluation is focused on the margin where there are clearly defined alternatives. In considering such a wide range of condition/treatment pairs, it is not clear where the relevant margin is. The question of, for example, the benefits of doing coronary artery bypass grafts (CABGs), is difficult to answer in the abstract, as their effectiveness will vary across patients with the extent of disease, age and risk factors. Economic evaluation is more usually applied to an analysis of whether there should be marginally more CABGs than hip replacements. The choice is not $\mathrm{CABGs}$ or hip replacements but what mix of CABGs and hip surgery will give the greatest health gains.

A priority list of disease/treatments constructed by the marginal approach does not imply that the treatment at the top of the list is more significant in saving lives or reducing morbidity than those lower down; rather it means that the additional health gain per dollar spent is higher for those disease/treatments at the top. This may explain why the draft priority list, released in September 1990 and withdrawn immediately by the HSC, did not look "intuitively sensible" to health care providers and consumers?

\section{Universal access}

It is important to realise that the availability of health care services for the majority of Oregon residents has not changed. Those covered by private health insurance continue to be covered. There is still differential access for those on welfare compared to those covered privately. This is quite in keeping with some contemporary thinking in the US that equity concerns can be met by the provision of a "decent basic minimum" of health care and that those who want special procedures or the ambience and comfort of "Cadillac care" should pay for it out of their own pockets. In Oregon, most of the citizens continue to drive health care Cadillacs.
The plan does extend access to health care (or at least to a designated list of essential treatments) to all citizens whose income falls below the federal poverty level. This is achieved without any budgetary increases in health care expenditure. The plan must cut back on expenditure elsewhere; it does this by limiting access to health care for current Medicaid beneficiaries and also to those services designated by the priority list. Therefore, to some extent, Medicaid beneficiaries are losers under the plan. But budgetary constraints at the federal level have led to successive tightening of the eligibility criteria for this program; thus a growing proportion of the poor are not eligible for Medicaid assistance. This may make the plan more politically acceptable.

\section{CONCLUSION AND RELEVANCE TO AUSTRALIA}

The rhetoric surrounding the Oregon experiment emphasises the provision of equitable health care, the restriction of health services based on cost-effectiveness analysis, and community consultation and the eliciting of community values in making those rationing decisions explicit. The implementation of the plan has fallen short of these ideals, as this review has described. The gap between rhetoric and reality has led some commentators to label the Oregon Plan an illusion4.

The plan is a solution to the growing numbers of citizens without guaranteed access to even basic health care. It is salutary to realise that the number of US citizens without any health insurance or entitlement to government benefits is larger than the population of Australia. In Australia, universal access to hospital and medical care is guaranteed and the system is financed largely through the ability to pay. Quite simply, although all countries have to face the issues of rationing health care, the Oregon problem is not the Australian problem.

Are there elements of Oregon which could be applicable here? The appeal of the experiment lies in its bold and explicit approach to rationing health care and its attempt to involve the community in the debate and decision making. Community consultation is a difficult issue. Asking individuals to rate lists of procedures makes little sense; they lack information about the efficacy and effectiveness of such interventions. What individuals can do is judge the worth or value of health gains as measured by the relief of pain, the improvement of mobility, the extension of survival and the reduction of anxiety. Survey methods and techniques already exist to collect this information. Individuals can also be asked to judge the value of health gains compared to other gains from health care, the provision of care rather than cure for the terminally ill and the enhancement of dignity and autonomy. These values can be taken into account in allocating health care resources.

Also important is the collection and dissemination of data on the costs and outcomes of treatments. There is little information on the long term outcomes of health care interventions, particularly their impact on the quality of life.

\section{Marion Haas, Public Health Officer Jane Hall, Director, Centre for Health Economics Research and Evaluation}

1. Kaplan RM, Bush JW, Berry CHC. Health Status: types of validity and the index of well-being. Health Serv Res 1976; 2:478.

the index of we Belling. Heall Serv Res 1976, 2:478. 2. Hadorn DC. Setting health care priorities in Oregon. Costiveness JAMA 1991; 265:2218-2225

3. Todd JS. Sounding board: is it time for universal access, not universal insurance. NE.JM 1989;321:46-7.

4. Warner W, Winkler F, Gritzner C. Best for Britain. Hlth Serv J; 1991: August 22. 19. 